\title{
Effects of debris on ice-surface melting rates: an experimental study
}

\author{
Natalya REZNICHENKO, ${ }^{1}$ Tim DAVIES, ${ }^{1}$ James SHULMEISTER, ${ }^{2}$ Mauri McSAVENEY ${ }^{3}$ \\ ${ }^{1}$ Department of Geological Sciences, University of Canterbury, Private Bag 4800, Christchurch, New Zealand \\ E-mail: natalya.reznichenko@pg.canterbury.ac.nz \\ ${ }^{2}$ School of Geography, Planning and Environmental Management, University of Queensland, St Lucia, \\ Queensland 4072, Australia \\ ${ }^{3}$ GNS Science, PO Box 30368, Lower Hutt, New Zealand
}

\begin{abstract}
Here we report a laboratory study of the effects of debris thickness, diurnally cyclic radiation and rainfall on melt rates beneath rock-avalanche debris and sand (representing typical highly permeable supraglacial debris). Under continuous, steady-state radiation, sand cover $>50 \mathrm{~mm}$ thick delays the onset of ice-surface melting by $>12$ hours, but subsequent melting matches melt rates of a bare ice surface. Only when diurnal cycles of radiation are imposed does the debris reduce the longterm rate of ice melt beneath it. This is because debris $>50 \mathrm{~mm}$ thick never reaches a steady-state heat flux, and heat acquired during the light part of the cycle is partially dissipated to the atmosphere during the nocturnal part of the cycle, thereby continuously reducing total heat flux to the ice surface underneath. The thicker the debris, the greater this effect. Rain advects heat from high-permeability supraglacial debris to the ice surface, thereby increasing ablation where thin, highly porous material covers the ice. In contrast, low-permeability rock-avalanche material slows water percolation, and heat transfer through the debris can cease when interstitial water freezes during the cold/night part of the cycle. This frozen interstitial water blocks heat advection to the ice-debris contact during the warm/day part of the cycle, thereby reducing overall ablation. The presence of metre-deep rock-avalanche debris over much of the ablation zone of a glacier can significantly affect the mass balance, and thus the motion, of a glacier. The length and thermal intensity of the diurnal cycle are important controls on ablation, and thus both geographical location and altitude significantly affect the impact of debris on glacial melting rates; the effect of debris cover is magnified at high altitude and in lower latitudes.
\end{abstract}

\section{INTRODUCTION}

The role of debris cover in modifying glacier behaviour is well known, but poorly understood as yet. Small-scale field studies have described enhanced (for very thin cover) to significantly reduced (for thicker cover) ice-surface ablation (e.g. Østrem, 1965; Lundstrom and others, 1993; Mattson and others, 1993). These field measurements are complemented by theoretical studies based on heat-flux calculations (e.g. Nakawo and Young 1981, 1982; Bozhinskiy and others, 1986). Broader field studies have shown that debris cover resulting from extensive, deep (metre-scale) dominantly finegrained rock-avalanche deposits can significantly affect mass balance of the glacier and cause it to advance (Post, 1968; McSaveney, 1975; Kirkbride, 1989; Hewitt, 2009) on decadal to centennial timescales in the absence of climate forcing. Thus not all terminal moraines result from climate alterations. Between these theoretical calculations and field observations, however, there is a dearth of information on the processes by which debris affects melt rates. Herein we describe laboratory experiments to investigate these processes, focusing on the roles of diurnal cyclicity and debris thickness and permeability in modifying melt rates under debris. These experiments aim to clarify the process details, rather than attempting to replicate field conditions in which other factors play a part. The objective is to isolate the effects of debris thickness and permeability on radiation- and rainfall-induced ice-surface melting.

A thin debris cover accelerates the melting rate of the underlying ice through increased absorption of solar energy by low-albedo debris and rapid transmission of this heat to the ice surface (Clark and others, 1994). Increasing debris thickness causes a corresponding decrease in the ablation rate; this was recognized in very early studies of glaciers by Agassiz (1840). Debris cover thicker than a particular depth acts as a barrier to heat transfer and decreases ice-melting rates with increasing debris thickness, leading to a reduction of the total underlying ice-surface ablation. From observations at many glaciers, a general relationship between debris-cover thickness and ablation has been developed (Mattson and others, 1993; Clark and others, 1994). In comparison with bare ice, mean daily ablation decreases exponentially with increasing debris thicknesses above the 'critical thickness'; this is defined as a debris depth at which melt rates are identical to those on adjacent bare ice (Adhikary and others, 1997; Nakawo and Rana, 1999).

Several numerical models have been proposed for calculating the insulating effect of debris cover (e.g. Khodakov, 1972; Nakawo and Young 1981, 1982; Bozhinskiy and others, 1986; Kayastha and others, 2000; Konovalov, 2000; Han and others, 2006; Nicholson and Benn, 2006). These are generally based on an energy balance for the debris layer. Ablation under the debris cover is usually calculated on the basis of heat conduction through the debris layer as a function of its thickness and the physical properties of the debris, or by comparison with the surface ablation of adjacent bare ice under the same conditions. McSaveney (1975) developed methods for calculating longterm ablation rates beneath thick debris, by analysis of the thermal conductivity of the debris layer as a function of 

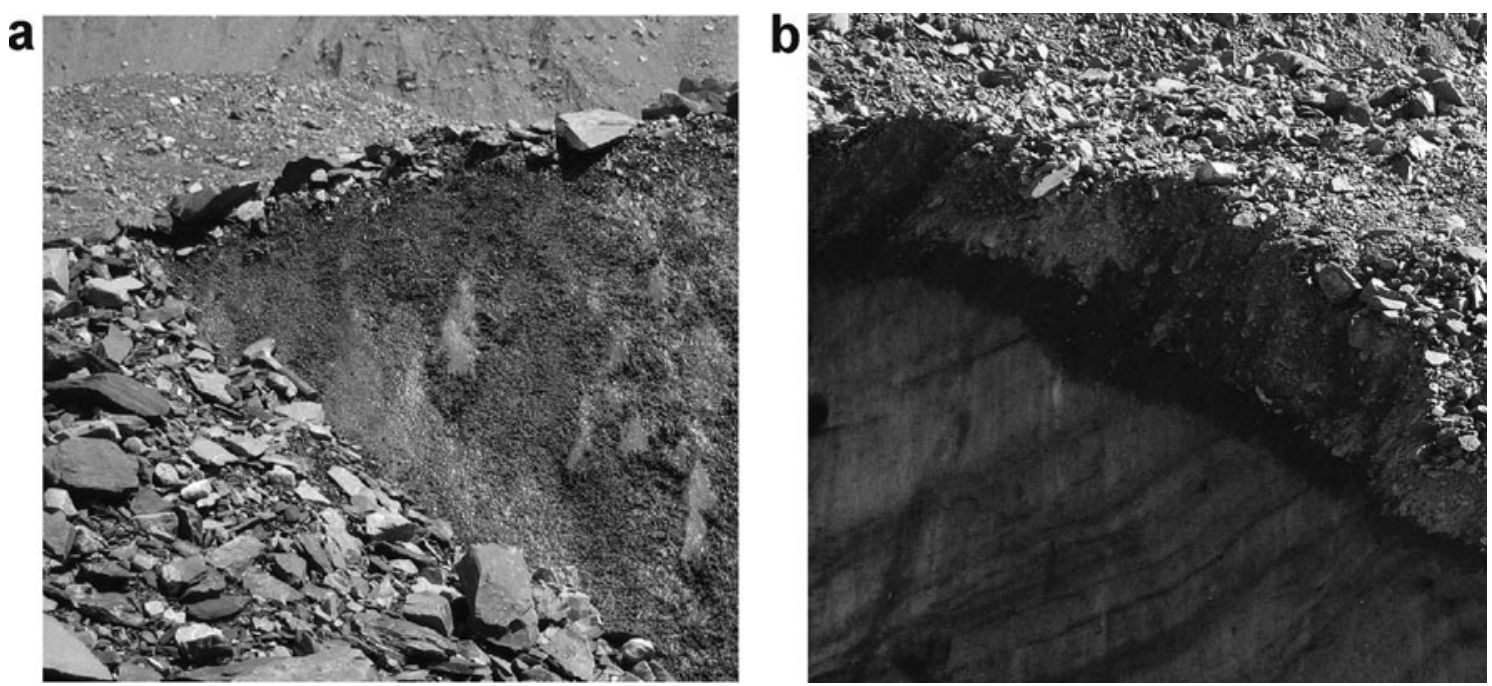

Fig. 1. (a) Meltout debris on Tasman Glacier, New Zealand. Note the thickness of the debris layer $(\mathrm{a}$ few $\mathrm{cm})$ and the relative lack of fines. (b) Rock-avalanche debris at the Mueller Glacier terminus, New Zealand, about 2-3 m thick. Fines are plentiful, and there is wet material at the ice contact.

debris thickness, thermal gradient, length of the ablation season and rainfall. None of these methods explicitly considers the effect of temporal variation of radiation, though many use a degree-day approach to estimate timeaveraged ablation.

Relatively few studies have considered the effect of rainfall on ablation rates, where the presence of percolating water can affect the heat flux through the debris layer itself and thus modify the ice-surface melt rate (McSaveney, 1975; Bozhinskiy and others, 1986; Röhl, 2008). It is established that rain and snowmelt contribute negligible heat to debrisfree temperate glaciers (Paterson, 1994); however, different thicknesses and properties of the debris cover will alter the contribution of rainfall to ablation beneath it. Thus the effect of the heat advection by rainfall through different debris depths may be significant and still needs detailed investigation. This study demonstrates the role of debris permeability in modulating ice-surface melt rates under rainfall.

All previous data describing ice ablation rates under debris cover have been derived from observations or experiments conducted on glaciers, and thus involve sitespecific physical parameters that may affect ablation. These observations were mostly obtained for small (and spatially varying) debris thicknesses, and the resulting models were based on parameters obtained from field observations or adjusted according to specific site conditions. Such approaches inevitably leave considerable uncertainty about the physical processes involved in ice-surface ablation beneath debris covers of different thicknesses. Herein we present the results of laboratory experiments on the effect of debris cover on underlying ice-surface ablation. This appears to be the first experimental approach to this problem; it directly measures the effect of a debris cover of known depth and physical properties on ice melt under controlled conditions, and provides potentially useful insights into the effects of debris on ablation rates under different insolation regimes.

We designed the experiments to test two specific hypotheses:

1. That the insulating effect of debris on ice depends on the occurrence of cyclic radiation input;
2. That the effect of rainfall on ice-surface ablation beneath debris is affected by the permeability of the debris.

\section{SUPRAGLACIAL DEBRIS}

Supraglacial ablation-zone debris cover has two distinct sources: englacial and extraglacial. The commonest source of ablation-zone debris is from meltout of englacial debris, which may itself be subglacially or extraglacially sourced (e.g. rockfall in the accumulation zone which is buried by snowfall (Sharp, 1949; Rogerson and others, 1986)). The resulting cover is thin (up to $10 \mathrm{~cm}$ thick and very variable in depth); it comprises usually angular clasts typically up to a few tens of $\mathrm{cm}$ in size (Fig. 1a). Externally sourced material is from rockfall onto the ablation-zone ice surface. Small rockfalls leave deposits that may appear similar to englacially derived cover, but are less areally uniform in depth. Large rockfalls (of the order of hundreds of thousands or millions of cubic metres, known as rock avalanches), however, leave distinctly different debris cover. This is usually one to several metres thick, has always been supraglacial, and comprises high proportions of very fine material below a 'carapace' of coarser material, giving it lower permeability than 'normal' (englacially derived) debris (Fig. 1a and b).

While there are certainly intermediate members, our experience on debris-covered glaciers in New Zealand is that these two types represent the majority of debris-cover occurrences. Most of the area of debris-covered glaciers is covered by the first type of debris. Rock-avalanche debris is less common. We do not consider terminal, medial or lateral moraines herein, as they occupy a relatively small proportion of glacier area.

In the laboratory, we used well-sorted medium greywacke river sand to represent normal (englacially derived) supraglacial debris; like normal supraglacial debris the material is highly permeable (Drewry, 1986) and has relatively low thermal inertia. To represent rock-avalanche debris we took material from below the carapace of the Coleridge rock-avalanche deposit, New Zealand (Lee and others, 2009). This material is typical of rock-avalanche 
a

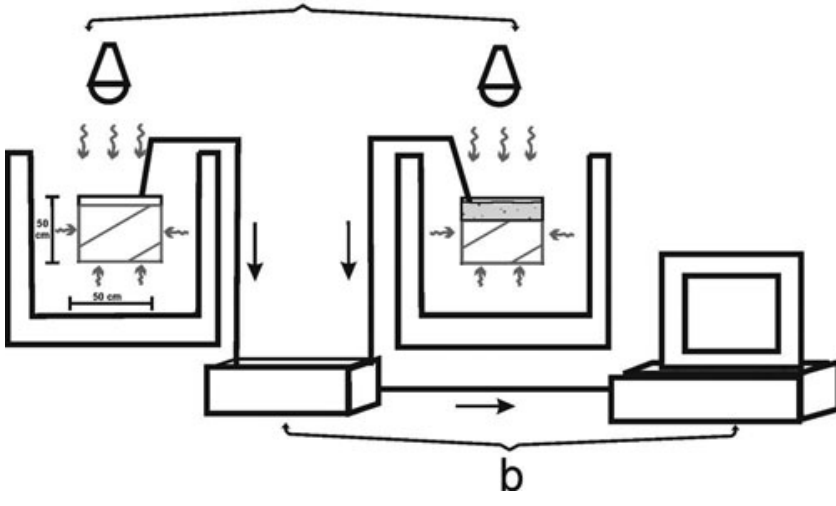

Fig. 2. The experimental arrangement for tests with diurnal cycles: (a) melting blocks of bare and debris-covered ice exposed to identical radiation during the 12 hour ablation period (attained by two electric bulbs with short- and longwave radiation, shown by grey lines) and cooling by freezer during the 12 hour night (shown by black lines); (b) Campbell Scientific 21X data logger and PC, which recorded temperature and heat-flux profiles.

debris: very widely (fractally) graded, with low permeability, and with coarser fragments embedded in pulverized matrix and containing abundant 'powder' (Hewitt and others, 2008). Being poorly sorted, it has a higher bulk density and thermal inertia than the sand. The contrast in properties between the sand and the rock-avalanche debris is similar to that between the two main types of supraglacial debris, so the difference in their effects on ice-surface ablation will be similar to that of the two types of supraglacial debris.

\section{EXPERIMENTAL METHODS}

The objective of the experiments was not to reproduce conditions on a glacier, but to study the processes by which the presence of overlying debris affects ice-surface melting due to incident radiation and rainfall. Thus we use radiation that may not correspond to specific glacial conditions in, for example, wavelength or incident angle, but we do use a realistic timescale for radiation cyclicity. Similarly the experimental debris in one case (sand) does not correspond in size range to supraglacial debris; we use two types of debris with identical lithology but very different grading and permeability, to represent the relevant differences between rock-avalanche debris and 'ordinary' supraglacial debris.

In the experiments, blocks of bare ice and identical blocks of ice with different thicknesses of debris cover were exposed to identical radiation (either constant or diurnally cyclic), and the differences in ice surface ablation rate were measured both with and without precipitation. The ice blocks (approximately $450 \times 350 \times 260 \mathrm{~mm}^{3}$ ) were made by freezing approximately $35 \mathrm{~L}$ of water in insulated containers; these containers had basal drains which were opened once freezing was complete. To simulate solar radiation, incandescent light bulbs with different light spectra (short- and longwave radiation of $350-750 \mathrm{~nm}$ wavelength using incandescent and warm white electric bulbs) were used simultaneously. Two types of debris were used as noted above, specific thicknesses of which $(10,50,90$ and $130 \mathrm{~mm}$ ) were uniformly placed on the ice surface.

Because the objective was to compare melt rates between bare and debris-covered ice under identical conditions, it was not necessary to monitor or control ambient conditions in the laboratory; however, debris-surface air temperatures gave a good indication of variations in ambient temperature. Air temperatures at the debris surface, within the debris layer and at the ice-debris interface were measured to $\pm 0.5^{\circ} \mathrm{C}$ with thermocouples and recorded on a Campbell Scientific 21X micrologger connected to a computer (Fig. 2). Heat-flux sensors measured the vertical local heat flow $\left(\mathrm{W} \mathrm{m}^{-2}\right)$ at the same positions as the thermocouples. All data were recorded at $10 \mathrm{~min}$ intervals. Ice-surface levels were measured at intervals of 12 hours with $\pm 2.5 \mathrm{~mm}$ accuracy, using a system of vertical strings frozen inside the ice blocks. Water discharge rates $\left(\mathrm{mL} \mathrm{h}^{-1}\right)$ of melted ice were recorded, which included ice-surface melting plus the (minimal) melting adjacent to the insulated sides and bottom of the container.

To examine the influence of debris cover on ablation rates, 'bare-ice' rates were compared with those under debris thicknesses of $10,50,90$ and $130 \mathrm{~mm}$. Two sets of experiments were conducted. In the first, bare and debriscovered ice blocks were exposed to identical steady continuous radiation until melting was complete. This we refer to as the 'steady-state' experiment, where the main aim was to see how the debris functions as an insulator. The second set of experiments examined the effects of diurnal temperature and radiation cycles, which were generated by alternately cooling the ice in chest freezers for half of the cycle and exposing it to radiation for the same length of time.

The experiments to study the effect of rainfall were conducted in a similar manner to the cyclic experiments, but with $10 \mathrm{~mm}$ depth of water sprayed onto the experiment each day over the course of 1 hour during the radiation part of the cycle. We used only the shortwave radiation bulb during this hour to eliminate longwave heating and replicate the cooling effect of cloud cover. We carried out two sets of rainfall experiments, one set with low-permeability rockavalanche debris and the other with high-permeability sand.

Note that rock-avalanche debris was not used in the nonrainfall tests, because using small depths of material (up to $130 \mathrm{~mm}$ ) would have been very unrealistic; rock-avalanche deposits on glaciers are rarely $<1 \mathrm{~m}$ thick (Shulmeister and others, 2009). We expect that the effect of rock-avalanche debris on ablation in the absence of rainfall would be similar to that of sand, with the higher thermal inertia due to the fines content increasing the delay before steady-state conditions are achieved. Considering the depth of rock-avalanche debris, we expect that, in reality, dry rock-avalanche debris would effectively cause ice-surface ablation to cease.

The data collected are presented as graphs of temperature profiles, heat fluxes, ice surface reduction rates, water discharge rates and coefficient of ice surface melting $(k)$ against time, for each debris-cover thickness. $k$ was defined as the ratio of the melting rates of debris-covered ice and bare ice:

$$
k=V_{\mathrm{d}} / V_{\mathrm{b}}
$$

where $V_{\mathrm{d}}$ and $V_{\mathrm{b}}$ are the melting rates of the debris-covered ice surface and the bare ice surface respectively.

\section{EXPERIMENTAL RESULTS}

\section{Steady-state conditions}

The first series of experiments with constant radiation and narrowly graded sand showed that previously reported rates of ice ablation, as a function of debris-cover thickness (e.g. 


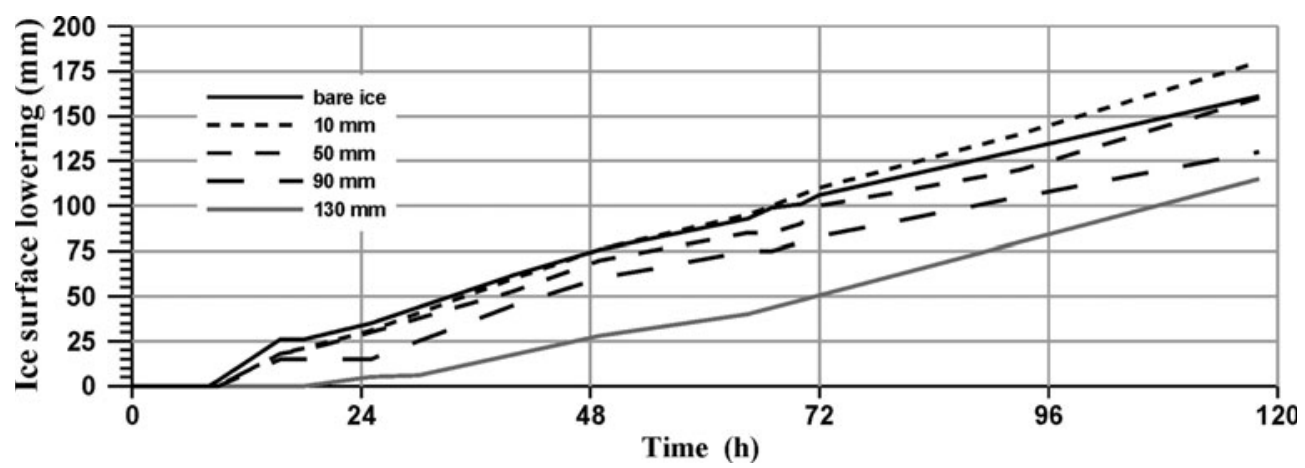

Fig. 3. Ice-surface lowering of bare ice and ice under 10, 50, 90 and $130 \mathrm{~mm}$ debris cover in steady-state conditions. The almost parallel lines after the initial period of heat-conduction stabilization through the debris and almost constant melt rates indicate the similar effect of different thicknesses of debris cover on ablation rates.

Østrem, 1965; Lundstrom and others, 1993; Mattson and others, 1993), corresponded in general with laboratory data at the start of the experiment; ice initially melted faster under $10 \mathrm{~mm}$ debris cover, and more slowly with thicknesses $\geq 50 \mathrm{~mm}$, than with bare ice. The reduction of melting rate under the thicker debris cover was primarily caused by the absorption of heat by the initially cold debris cover at the beginning of the experiment, which delayed and retarded the melting of the underlying ice. Once heat conduction through the debris achieved a steady state, and the melting rate became constant, the ice-ablation rates under different debris-cover thicknesses and with bare ice were fairly similar (Fig. 3); the melting rate with bare ice was about $10 \%$ less than with $10 \mathrm{~mm}$ of debris, presumably an albedo effect.

The effect of the debris in slowing the melting rate prior to stabilization varied in direct relationship to its thickness. Additionally, thicknesses greater than $90 \mathrm{~mm}$ delay the onset of melting significantly. The onset of ice melting under $130 \mathrm{~mm}$ of debris was delayed $>12$ hours and the system stabilized only after 60 hours (Fig. 4). The duration of retarding of the melting rates depends on the initial condition of the system (e.g. debris thickness, its physical properties and the initial debris temperature) and on the radiation intensity.

These results show that, under constant radiation, significant debris cover delays the occurrence of steady-state ablation, but once this occurs, the debris does not affect it. In particular, under steady-state conditions it took $>12$ hours to establish constant heat conduction and to achieve the same ablation rates as those for bare ice with a debris layer thicker than $50 \mathrm{~mm}$ (Fig. 4). This suggests that under diurnally cyclic radiation, steady-state heat transmission may never occur through debris of this thickness. We therefore investigated the ablation of ice beneath debris layers under diurnally cyclic radiation and cooling.

\section{Diurnal cycles}

Under diurnal cycles, the time-averaged melt rate was slower, so it took longer to melt the ice than under steadystate conditions (Fig. 5). As suggested by the steady-state tests, with debris thicknesses $>50 \mathrm{~mm}$, a stable heatconduction profile, in which the debris thickness does not affect melting rates, was never achieved under diurnal cycles (Figs 6 and 7).

Heat-flux and temperature-profile changes through the debris layer clearly show the effect of the debris layer on heat conduction (Fig. 6). After the ablation period of the cycle, when radiation ceases and cooling begins, the system temperature decreases. However, due to the heat capacity of the debris, it takes longer than the cooling part of the cycle to fully cool the debris. With every cycle these processes recur, and consequently the system never reaches a steady state. Figure 6 shows examples of the temperature profiles and heat fluxes for one cycle through different debris thicknesses in comparison with noncyclic experiments, where with 90 and $130 \mathrm{~mm}$ of debris layer the overall melting of ice is significantly slower under diurnal conditions.

During all experiments the basal part of the debris layer consistently became saturated with meltwater; and in steady-state experiments, depending on the debris thickness, the whole debris cover became saturated after a time. In the

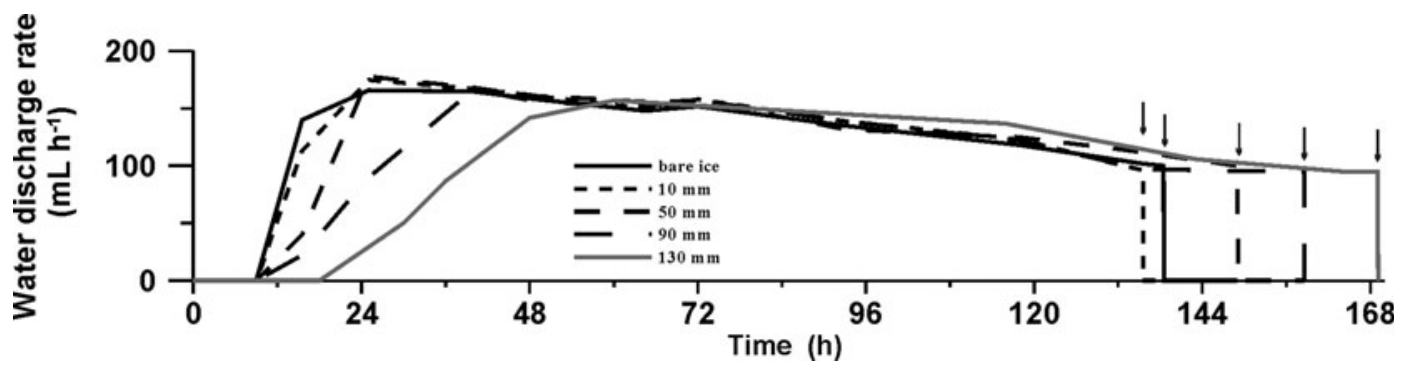

Fig. 4. Water-discharge rates for bare ice and ice under 10, 50, 90 and $130 \mathrm{~mm}$ debris cover in steady-state conditions, where the arrows indicate the end of melting for bare ice and ice under debris of different thicknesses (note also the different initial rates of melting under different thicknesses of debris). The decrease of melt rate with time is caused by the increasing distance of the ice or debris surface from the radiation source as melting proceeds. 


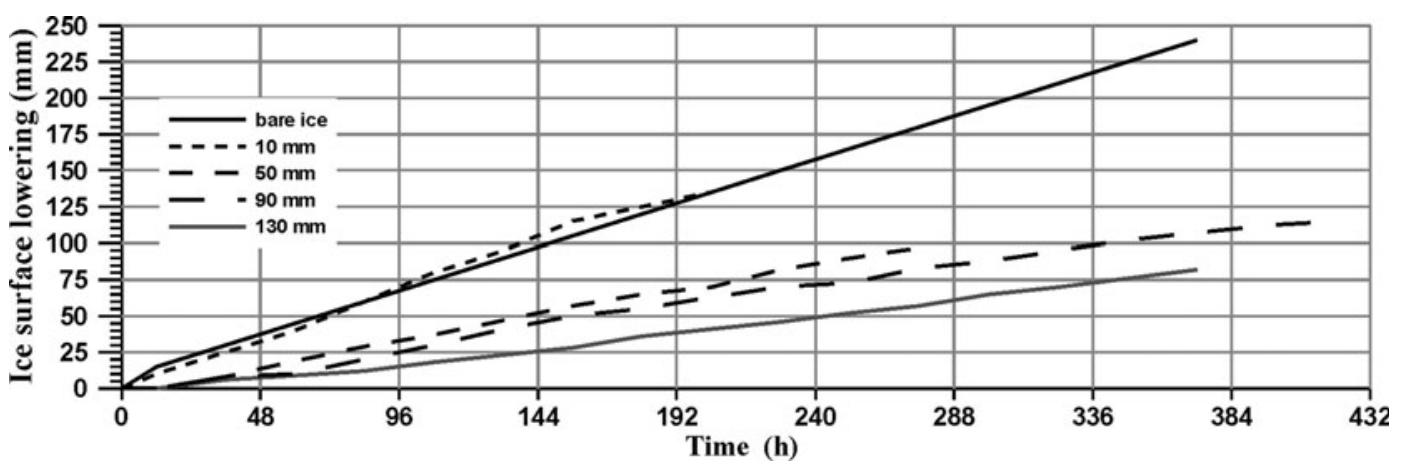

Fig. 5. Ice-surface lowering of bare ice and ice under debris cover of 10, 50, 90 and $130 \mathrm{~mm}$ under diurnal-cycle conditions; note the duration of the experiments and different slopes of the ice-surface lowering lines in comparison with steady-state conditions (Fig. 3). In both sets of experiments the initial ice volumes were equal; however, the diurnal-cycle experiments were not all run to the end of melting.

diurnal-cycle experiments, this process was significantly retarded and it took of the order of days to saturate the debris layer to $>50 \mathrm{~mm}$ from the ice surface.

The results from all non-rainfall experiments are summarized and presented in Figure 8. For each experiment the average coefficient of ice-surface melting $(k)$ was calculated and plotted according to the debris layer thicknesses. Although the average $k$ for the steady-state conditions was calculated from data after stabilization of the heat flux through the debris and melting rates, the average $k$ for the ice under cyclic conditions remains significantly lower.

\section{Effect of rainfall}

Rainfall experiments were conducted with two different debris materials: one of these was narrowly graded medium sand with high permeability $\left(1.6 \times 10^{-3} \mathrm{~m} \mathrm{~s}^{-1}\right)$, used in the other experiments; the other was rock-avalanche material with lower permeability $\left(1.8 \times 10^{-7} \mathrm{~m} \mathrm{~s}^{-1}\right)$. Rain percolated through the medium sand and reached the debris-ice interface in about 1 hour, and caused the melting rate under the debris cover to increase (Fig. 9). Melting rates under the debris were higher than those with no rainfall because percolating rain advects heat from the warm debris to the ice. The sand used in our experiments is intended to represent thin supraglacial material, which also has a high permeability, and has a similar effect on ice-surface ablation. Because rainfall accelerates the ablation of the bare ice to almost the same degree as with debris cover (Fig. 9), it could be concluded from our experiments that the rainfall has the same effect on a clean glacier as on a glacier with a thin supraglacial layer of highly permeable debris cover.

The experiment was then repeated using $90 \mathrm{~mm}$ depth of rock-avalanche material instead of sand. Rock-avalanche material differs from ordinary supraglacial debris by the much greater proportion of very fine (micron-scale) material, which remains preserved within the avalanche deposit below the noticeably coarser carapace (McSaveney and Davies, 2007; Shulmeister and others, 2009), and, as a result, it has low permeability. It is also usually much deeper (of the order of 1-5 m; Shulmeister and others, 2009) than normal supraglacial debris sourced from meltout of englacial debris. Our experiment had an unrealistically small

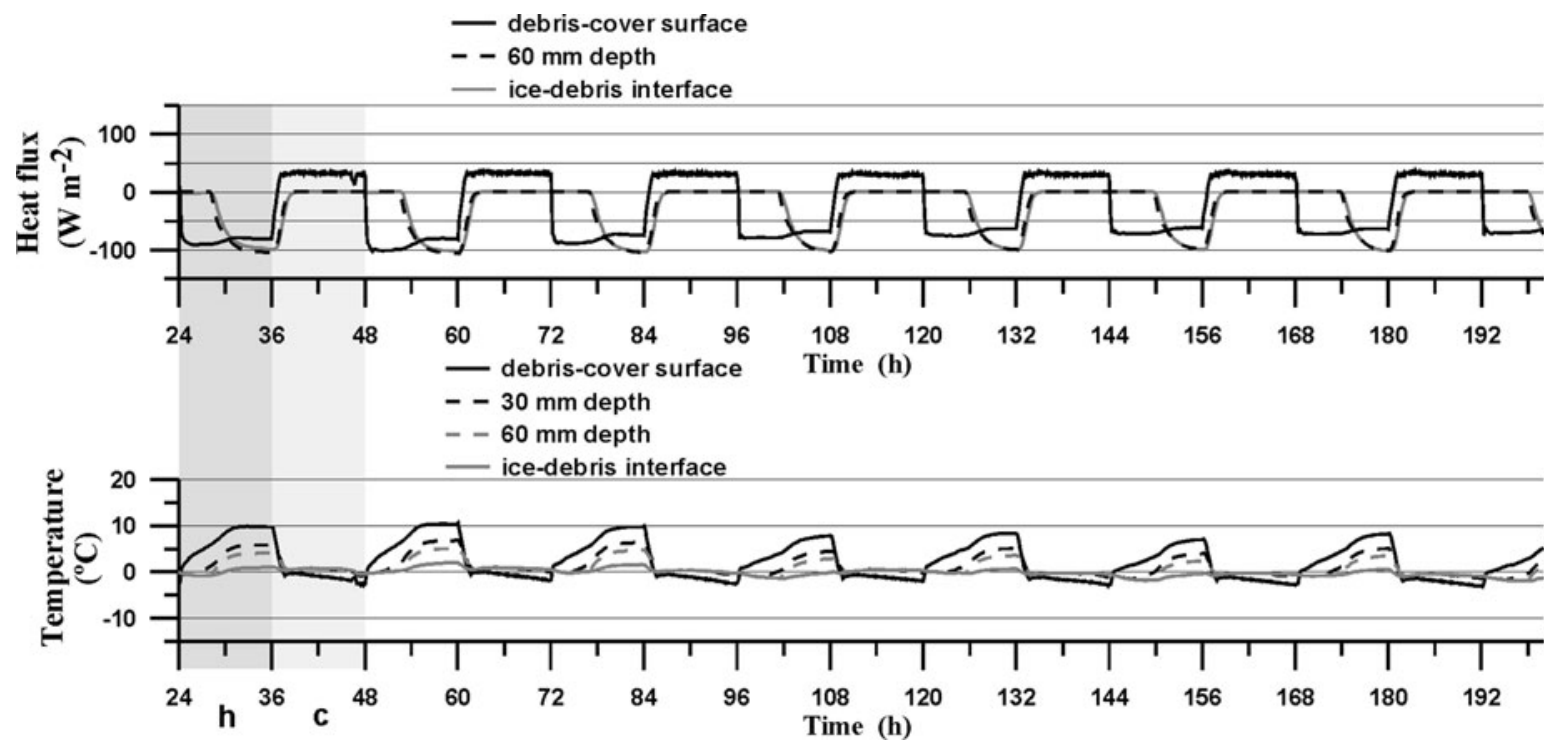

Fig. 6. Examples of heat fluxes and temperature profiles through a $90 \mathrm{~mm}$ debris layer (at debris-cover surface, at depths of $30 \mathrm{and} 60 \mathrm{~mm}$ and at ice-debris interface) under diurnal-cycle conditions. ' $\mathrm{h}$ ' indicates the heating part of the cycle with radiation exposure, and ' $\mathrm{C}$ ' indicates the cooling part of the cycle. Heat-flux profiles show the delayed response of the deeper layer of the debris to radiation exposure during the ablation period of the cycles, where it takes $>6$ hours (half the period) to start heat conduction through the whole layer. Note the same trend in the temperature profiles, where as a result the temperature variation decreases towards the ice-debris interface. 

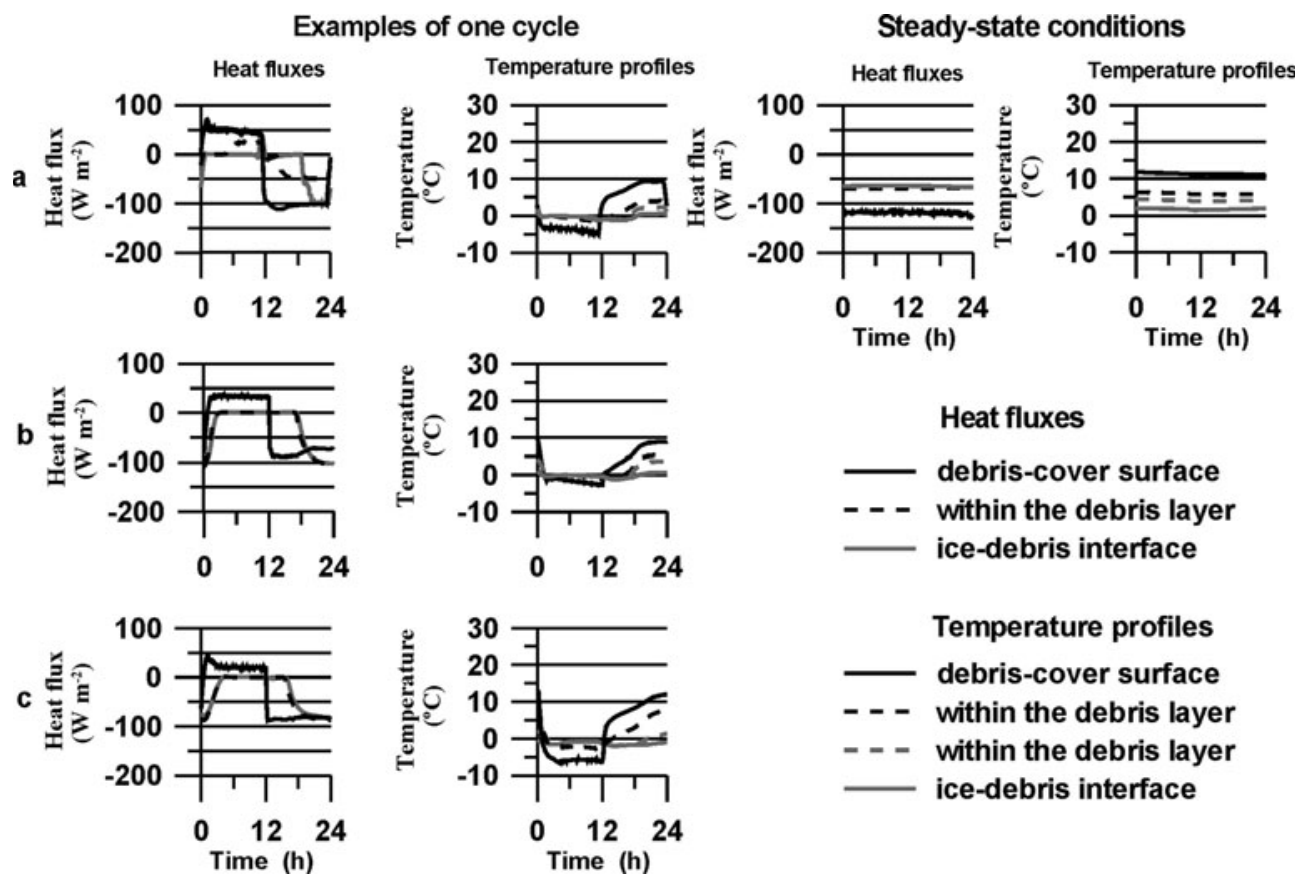

Fig. 7. Examples of one cycle (24 hours) of temperature profiles and heat fluxes through debris-cover thicknesses of $50 \mathrm{~mm}$ (a), $90 \mathrm{~mm}$ (b) and $130 \mathrm{~mm}$ (c), where the first 12 hours of the cycle is a cooling part, in comparison with the steady-state temperature profiles and heat fluxes through $50 \mathrm{~mm}$ debris-cover thickness. Note the constant heat transmission through the layer under steady radiation in comparison with changes under diurnal cycles.

depth of rock-avalanche material, so the effects we noted would be increased by the usually much greater depth.

During the experiments with rain on rock-avalanche material, cyclicity played a crucial role. The rate of heat advection by rain through the rock-avalanche debris was very slow because saturation of the initially dry debris layer required longer than the 12 hour ablation period, so the debris was unable to transmit heat by water to the debris-ice interface. Furthermore, during the cooling period of the cycle, the saturated layer of debris froze, and consequently, during the next cycle, normal heat percolation through the debris layer was delayed because extra energy was needed to melt the interstitial water in the debris. In this case, the start of ice ablation under the rock-avalanche debris cover was significantly delayed; in fact, in our study, ablation did not initiate (i.e. the ice-surface temperature never rose to $0^{\circ} \mathrm{C}$; Fig. 10). This contrasts with the acceleration of ablation

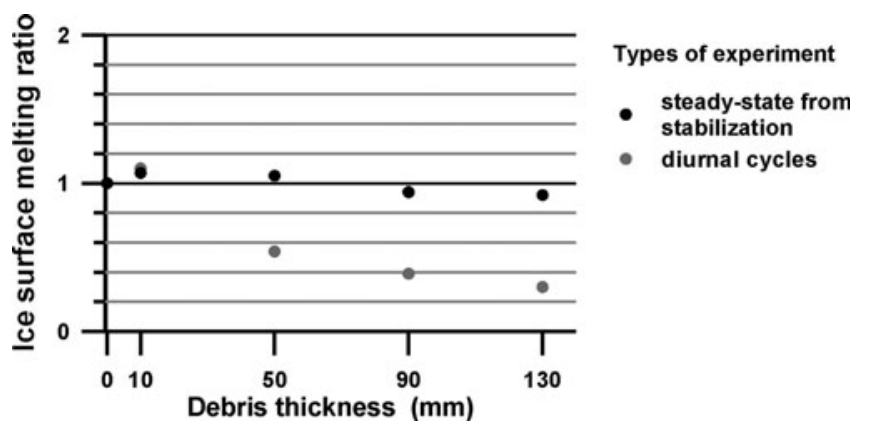

Fig. 8. Average coefficients of ice-surface melting ratio $(k)$ for bare ice and ice under 10, 50, 90 and $130 \mathrm{~mm}$ of sand debris cover. Black points: steady-state experiments after the heat flux through the debris layer stabilized; grey points: cyclic experiments. with rainfall under a $90 \mathrm{~mm}$ sand cover (Fig. 9). It is concluded that debris permeability is a crucial parameter that affects ablation during rainfall, and the direction and intensity of the effect will depend on the amplitude of the diurnal cycles, the duration of the part of the cycle that is below $0^{\circ} \mathrm{C}$, and debris-cover thickness at a particular glacier. In particular, the presence of rock-avalanche debris can significantly reduce rainfall-generated ice-surface ablation.

\section{DISCUSSION}

The experimental data indicate clearly (1) the importance of the diurnal radiation cycle, and (2) the importance of debris permeability, on the rate of ice-surface ablation beneath a debris cover due to radiation and rainfall, supporting our hypotheses. The direct application of the laboratory data to any specific glacier, however, would be unrealistic due to

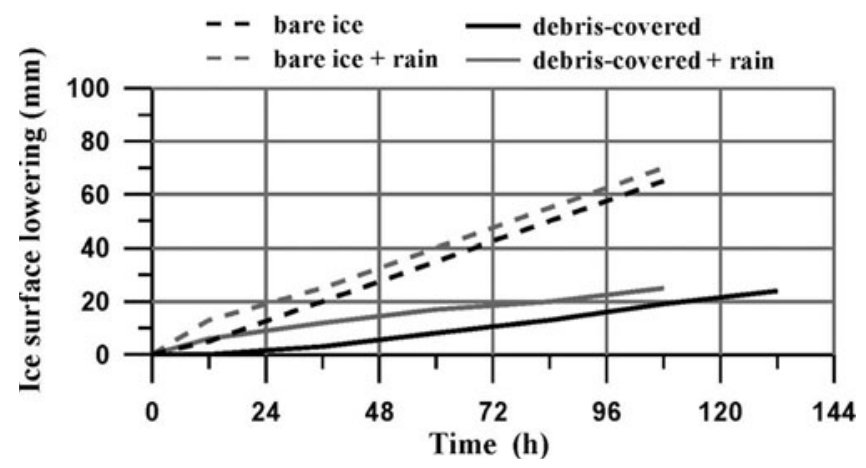

Fig. 9. Examples of the ice-surface level lowering beneath $90 \mathrm{~mm}$ of sand and with bare ice under cyclic conditions; and also with bare ice and with ice covered with $90 \mathrm{~mm}$ of sand, with $10 \mathrm{~mm}$ of water sprayed onto the surfaces daily. 

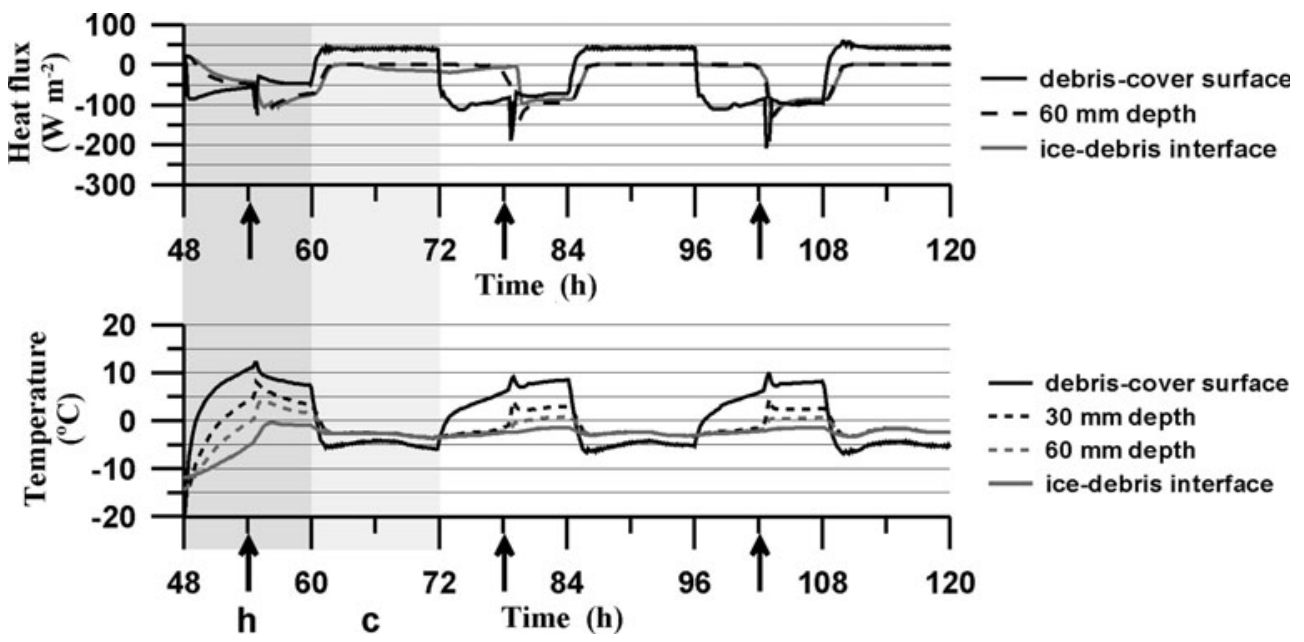

Fig. 10. Examples of the heat-flux and temperature-profile changes through $90 \mathrm{~mm}$ of rock-avalanche debris layer under diurnal-cycle conditions with rainfall of $10 \mathrm{~mm} \mathrm{~d}^{-1}$. Temperature at the ice-debris interface (grey solid curve) during the experiment remains negative and does not reach melting point due to very slow heat conduction through saturated frozen rock-avalanche debris. ' $h$ ' indicates the heating part of the cycle with radiation exposure, ' $c$ ' indicates the cooling part of the cycle and arrows indicate the occurrence of rainfall during the cycles.

the idealized laboratory conditions required for testing specific hypotheses. On a glacier, a wide range of additional effects occur that will potentially affect ice-surface ablation, including variations in intensity, wavelength and angle of incidence of radiation; variations of temperature and humidity different from those in the laboratory; sensible heat and upwelling longwave radiation fluxes; wind; spatial variations in debris thickness and composition; varying rainfall; and ice motion. Evidently, realistic reproduction of specific field conditions in the laboratory is extremely difficult, so we have concentrated on investigating some basic processes. Nevertheless, as demonstrated below, laboratory data indicate that diurnal cyclicity is crucial to insulation under debris, and suggest that the global variation of diurnal cyclicity may be a significant parameter in the global variation of glacier-surface insulation by debris.

\section{Diurnal radiation cycles and debris properties}

The steady-state experiments showed that melting of the underlying ice begins with different rates for different debris thicknesses, whereas, after the system achieves a steady state or stabilizes (which takes longer with greater debris depths), melting rates are similar under different debris depths. The main conclusion is that the debris cover delayed the onset of steady melting but did not significantly affect overall icemelting rates after the stabilization of the heat conduction profile through the debris layer. By contrast, under diurnal cycles, when the system is repeatedly exposed to changing environmental conditions, these delays in response, repeated daily, result in the insulating effect of the debris cover on the glacier ice.

This suggests that the ablation rates of ice under debris will vary with the relative amplitudes and durations of the heating and cooling parts of the radiation cycle, because these determine the degree of insulation effect of the debris cover. In other words, a given depth of given debris has a particular thermal inertia; the duration and intensity of the radiation cycles, relative to this inertia, determine the delivery of energy to the underlying ice and thus the melt rate.

The diurnal cycles also affected melting rates under debris cover with rainfall. The extra energy input to a glacier due to rainfall above $0^{\circ} \mathrm{C}$ was pointed out by Paterson (1994) in calculating the effect of rainfall on ablation rates of clean ice, but he considered these effects insignificant in massbalance changes of the glacier. It is to be expected, however, that when water can percolate through sun-warmed debris to the ice surface, melt will be enhanced, as we found. An unexpected effect was that the low-permeability rockavalanche debris not only reduced the enhanced melting effect of the rainfall; as a result of the freezing part of the cycle, it reversed that effect and, in our laboratory conditions, led to the cessation of ablation under the debris. Evidently, freezing may not be a universally occurring effect, depending on debris depth, permeability and diurnal cycle characteristics. However, the fact that it may occur indicates that radiation intensity and duration (cyclicity) and debris permeability need to be included in the estimation of ablation rates under debris cover, rather than using only debris depth and daily average values of radiation (e.g. Kayastha and others, 2000; Mihalcea and others, 2006).

\section{Critical thickness and diurnal cyclicity}

The critical thickness (defined as the thickness at which the underlying ice ablation equals that of adjacent bare ice, and with increase of which the debris has an insulation effect on the underlying ice) has been reported at a number of glaciers round the world (Table 1). Critical thickness is determined by the same parameters that determine total ice-surface ablation, so consistent trends in critical thickness indicate consistent trends in debris insulation of underlying ice. Despite the presence of significant local effects, the global distribution trends of critical thicknesses are quite distinct (Fig. 11), and indicate the general trend of the effect of debris cover on glacier-surface ablation; this must reflect the effect of radiation cycle variability, since noise from local effects will be more-or-less randomly distributed. Numerous field experiments on snowmelt under dust show that critical thickness increases linearly with increasing average solar energy input rate (Adhikary and others, 1997).

Our experiments demonstrated the crucial role of diurnal cyclicity in generating the insulating ability of debris cover. Therefore we expect the variability of global radiation 


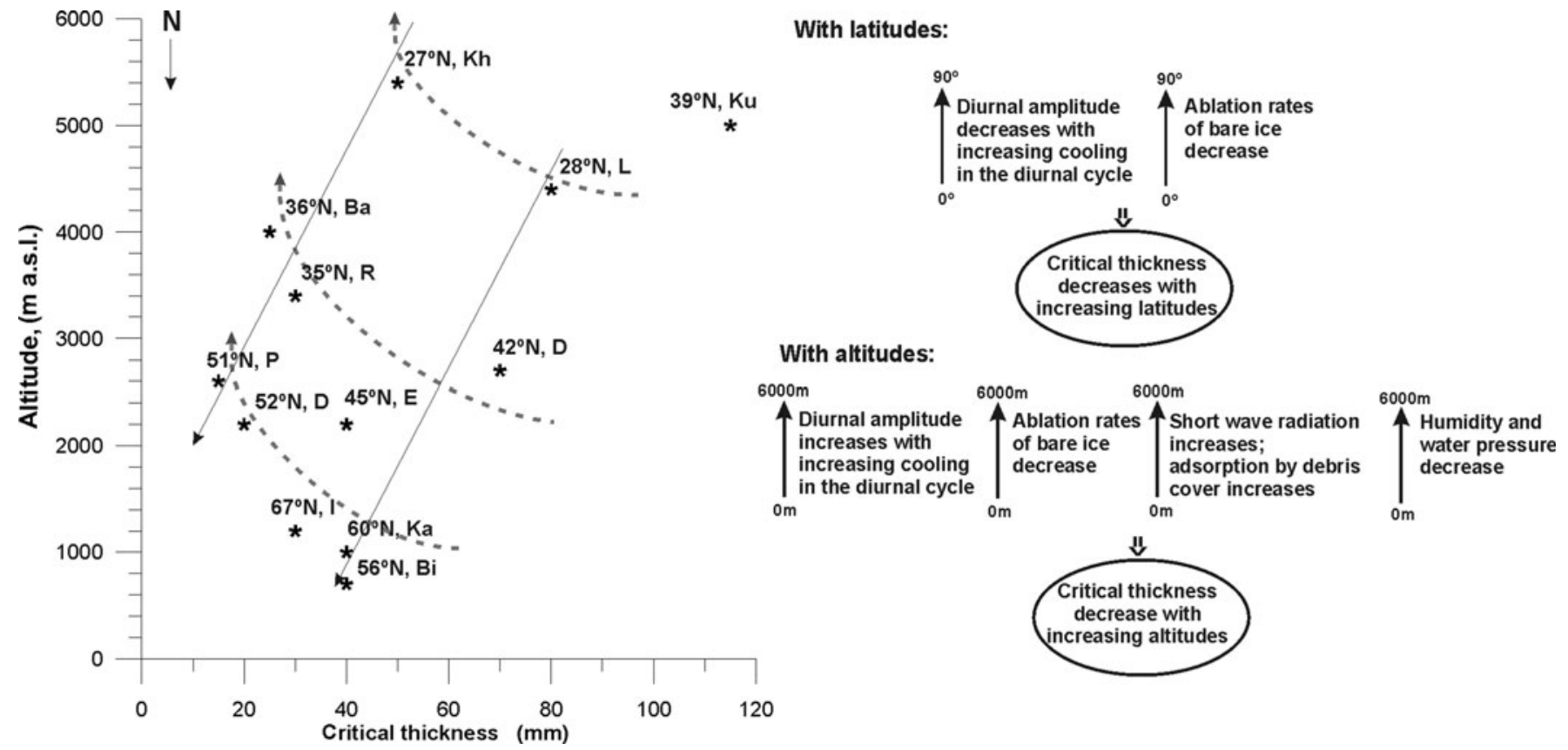

Fig. 11. Critical thicknesses $(\mathrm{mm})$ are varying with altitude (ma.s.l.) and latitude (Northern Hemisphere) from the available observed data (Table 1). The critical thickness of the equivalent latitudes (dashed lines) decreases with increasing elevation. Kh: Khumbu Glacier, Nepal (Kayastha and others, 2000); Ku: Kul'dgilga glacier, Kyrgyzstan (Demchenko and Sokolov, 1982); L: Lirung Glacier, Nepal (Tangborn and Rana, 2000); Ba: Barpu glacier, Pakistan (Khan, 1989, in Kirkbride and Dugmore, 2003); R: Rakhiot glacier, Pakistan (Mattson and Gardner, 1989); D: Djankuat glacier, Russia (Popovin and Rozova, 2002); E: Eliot Glacier, Oregon, USA (Lundstrom and others, 1993); P: Peyto Glacier, Canada (Nakawo and Young, 1981); D: Dome and Athabasca Glaciers, Canada (Mattson, 2000); I: Isfallsglaciären, Sweden (Østrem, 1965); Ka: Kaskawulsh Glacier, Canada (Loomis, 1970, in Kirkbride and Dugmore, 2003); Bi: Bilchenok glacier, Russia (Yamaguchi and others, 2000, 2007).

cyclicity to be reflected in debris-cover insulation, and Figure 11 shows that global solar-energy input cyclicity (varying with latitude and elevation) indeed correlates well with critical thickness. Although most of the field observations in Table 1 were conducted during the maximum-ablation seasons of the glaciers, local factors (e.g. meteorological conditions, slope orientation and shading, measurement technique) will cause significant differences in ablation rates. However, the general trends of Figure 11 are clear and must be controlled by the radiation cycles; the critical thickness decreases with increasing latitude and increasing elevation.

The decrease of the critical thickness with increasing latitude is explained by the decreasing amplitude of the diurnal cycle with increasing latitude, and the corresponding decrease of average temperatures (Barry, 2008). With increasing altitude the diurnal amplitude increases, due to enhanced outward radiation (Oerlemans, 2001) and lower

Table 1. Measured critical thicknesses on glaciers; critical thickness is thickness at which sub-debris ablation rate equals ablation of adjacent bare ice

\begin{tabular}{|c|c|c|c|c|c|}
\hline Glacier & Country & $\begin{array}{l}\text { Latitude } \\
{ }^{\circ} \mathrm{N}\end{array}$ & $\begin{array}{c}\text { Elevation } \\
\text { ma.s.l. }\end{array}$ & $\begin{array}{l}\text { Critical thickness } \\
\qquad \mathrm{mm}\end{array}$ & Source \\
\hline Khumbu & Nepal & 27.57 & 5400 & 50 & Kayastha and others (2000) \\
\hline Lirung & Nepal & 28.13 & 4400 & 80 & Tangborn and Rana (2000) \\
\hline Rakhiot & Pakistan & 35.21 & 3400 & 30 & Mattson and Gardner (1989) \\
\hline Barpu & Pakistan & 36.11 & 4000 & 25 & Khan $(1989)^{*}$ \\
\hline Kul'dgilga & Kyrgyzstan & 39.30 & 5000 & 115 & Demchenko and Sokolov (1982) \\
\hline Djankuat & Russia & 42.12 & 2700 & 70 & Popovnin and Rozova (2002) \\
\hline Eliot & USA & 45.23 & 2200 & 40 & Lundstrom and others (1993) \\
\hline Peyto & Canada & 51.41 & 2600 & 15 & Nakawo and Young (1981) \\
\hline Dome & Canada & 52.12 & 2200 & 20 & Mattson (2000) \\
\hline Athabasca & Canada & 52.12 & 2200 & 20 & Mattson (2000) \\
\hline Bilchenok & Russia & 56.10 & 700 & 40 & $\begin{array}{l}\text { Yamaguchi and others (2000, } \\
\text { 2007) }\end{array}$ \\
\hline Isfallsglaciären & Sweden & 67.54 & 1200 & 30 & Østrem (1965) \\
\hline
\end{tabular}



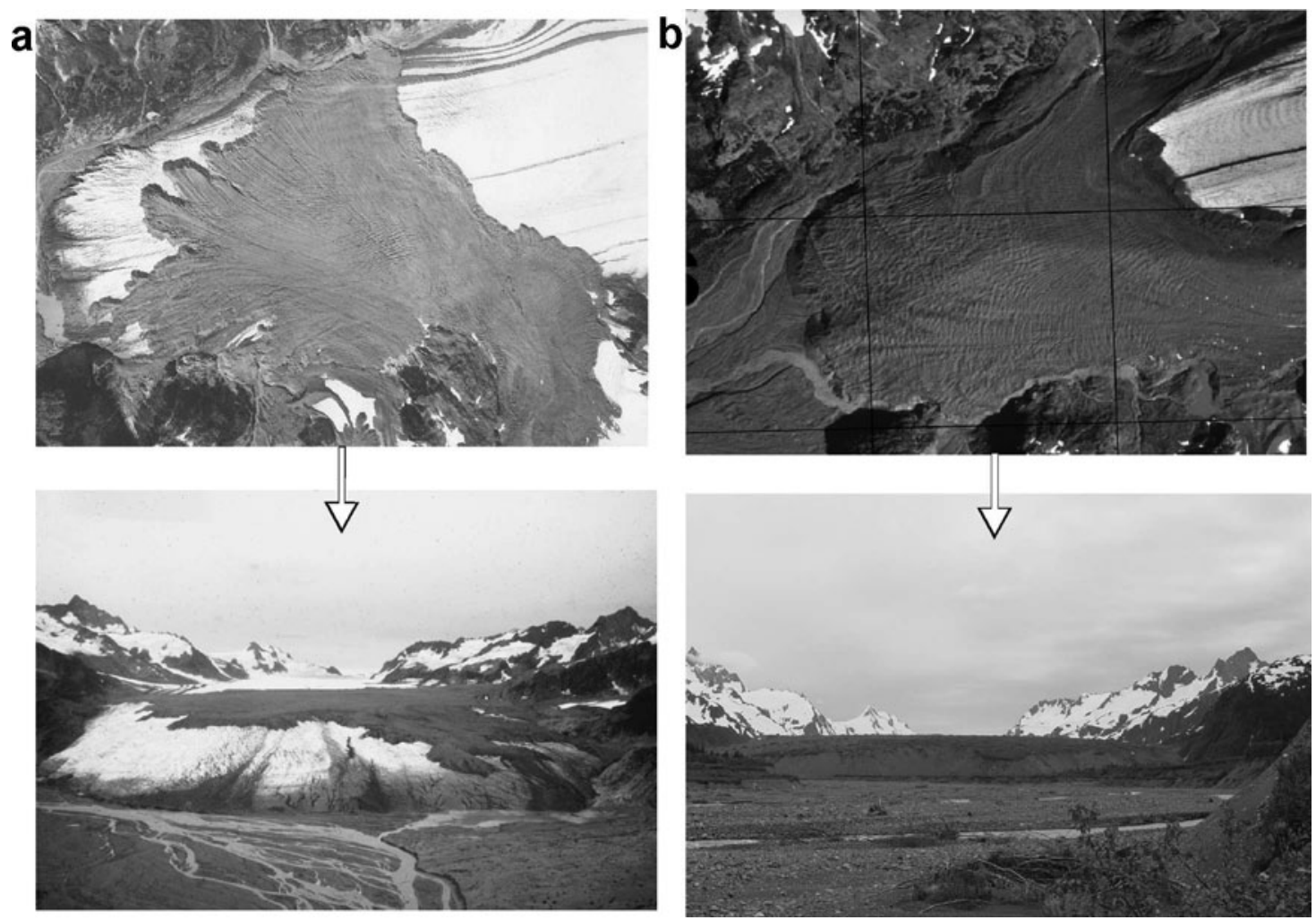

Fig. 12. The rock avalanche caused by the 1964 Great Alaska Earthquake covered part of the ablation zone of Sherman Glacier. (a) The rockavalanche cover after its emplacement in 1967. (b) The rock avalanche reached the terminus of the glacier in 2008 (pictures from McSaveney).

temperatures at night. Absorption of shortwave radiation by thin low-albedo debris cover during the day exceeds absorption by bare ice (Slaymaker and Kelly, 2007); however, the lower night-time temperatures enhance the insulation effect of thicker debris covers, leading to increasing requirement for heat percolation through the debris during the next day to restart ablation. Figure 11 suggests that at a given latitude there tends to be a slight decrease of the critical thickness with increasing elevation; this indicates that factors such as reduced atmospheric and vapour pressure, humidity, and the frequency of below-freezing temperatures outweigh the effect of enhanced daytime radiation. This corresponds to the decrease of annual mean ablation rate for bare ice with increasing latitude and elevation found by Budd and Allison (1975, fig. 1).

Another factor that influences the intensity of the diurnal cycles is the degree of continentality of the climate. Continental climates are characterized by less cloudiness and consequently greater shortwave radiation in the glaciersurface heat budget than maritime climates (Oerlemans, 2001). Under continental conditions the low-albedo debris cover absorbs more shortwave radiation and the debriscover insulation properties are reduced, which may explain high critical thickness in the Pamir mountains at Kul'dgilga glacier where very little cloud occurs and annual precipitation is low.

There is a general correlation between radiation cycle amplitude and intensity, and global distribution of critical thickness that is logical in terms of the processes considered. Other factors and processes (e.g. meteorological conditions, debris-cover lithology and continuity, slope orientation and shading, roughness, measurement technique, etc.) may affect the distribution, but Figure 11, like the experimental data, supports our hypothesis that radiation cyclicity is important in determining ice-surface ablation under debris.

\section{Application: debris cover and glacier mass balance}

Our experimental results suggest that debris cover should have a greater effect on ablation, and thus on mass balance and glacier behaviour, in areas with strong diurnal cycles such as the Karakoram Himalaya, compared with areas of lower diurnal variability at higher latitudes, all other things being equal. In a similar analysis of data from four glaciers Mattson and others (1993) concluded that the location of the glaciers will affect the intensity of the ablation (or the quantity of melted ice) with differences in debris-cover thickness. They point out that glaciers located at low latitudes or high elevations will receive more energy per unit time; however, when the debris cover becomes relatively thick, the location becomes less important due to the overwhelming influence of the debris cover.

If the debris cover significantly reduces ablation rates, the behaviour of a glacier will to some extent become less dependent on climate (Hewitt and others, 2008). The reduced surface melt in the ablation zone of a rockavalanche-covered glacier causes ice to thicken due to slower ablation (McSaveney, 1975). Thus, a large area of thick ice persisted on Bualtar glacier, Karakoram (Hewitt, 2009), where rock-avalanche debris cover reduced ablation, and had an impact on mass balance equivalent to a $20 \%$ increase in annual accumulation. The relatively thin rock avalanche deposited on Sherman Glacier by the Alaska earthquake of 1964 (1.5 m deep on average; McSaveney, 1975) covered $50 \%$ of the ablation zone and altered the mass balance of the glacier from negative to slightly positive (Post, 1968; McSaveney, 1975), and the glacier is still 
advancing some 45 years after the event (Fig. 12). Shulmeister and others (2009) point out that such landslidedriven advances (and their subsequent retreats) can generate terminal moraines which can be misidentified as climatedriven, and spurious palaeoclimatic inferences could be drawn; given the crucial role of glacial palaeoclimatology in understanding the likely effects of anthropogenic climate change, improved understanding of the effect of supraglacial debris on ablation, and hence mass balance, is important.

\section{CONCLUSIONS}

We have carried out the first laboratory experiments comparing ablation from bare ice with that from debriscovered ice, investigated the effects of debris permeability and of rainfall, and suggested on this basis that variations in diurnal cyclicity contribute significantly to the known global distribution of critical thickness (a surrogate for the insulating effect of debris).

We conclude that:

1. The strength of the diurnal cycle plays a significant role in controlling the rate of melting beneath debris:

in the absence of diurnal variability of radiation, the primary role of debris cover is to delay the onset of steady ice surface melting; once melting rates stabilize, the debris has no further significant effect;

under cyclic diurnal radiation, a long-term reduction in ablation rate occurs, and the degree of reduction is controlled by the debris-cover thickness.

2. The effect of rainfall on ice ablation under debris depends both on diurnal cyclicity and on the permeability of the debris cover:

high-permeability thin supraglacial debris cover accelerates ablation from the ice surface to a similar degree to that from clean ice under rainfall;

rock-avalanche debris is relatively impermeable and under particular conditions can dramatically reduce ablation rates with daily rainfall.

3. Ice-surface ablation rates are conditioned by debris cover due to variations in diurnal cycle intensity and thus geographical location because:

debris cover retards ice-surface ablation when its thickness exceeds the critical thickness for a given glacier;

the critical thickness generally decreases with increasing latitude and with increasing elevation.

4. The effect of debris cover on the mass balance of a glacier depends on the permeability and dimensions (thickness and proportion of ablation zone covered) of the deposit together with the diurnal-cycle amplitude at the particular location.

5. Understanding the role of supraglacial debris on mass balance is crucial in distinguishing terminal moraines which reflect climatic change from those caused by debris-cover induced advance.

\section{REFERENCES}

Adhikary, S., K. Seko, M. Nakawo, Y. Ageta and N. Miyazaki. 1997. Effect of surface dust on snow melt. Bull. Glacier Res., 15, 85-92.

Agassiz, L. 1840. Études sur les glaciers. Neuchâtel, Jent et Gassmann. Transl. in Studies on glaciers, preceded by the discourse of Neuchâtel, ed. A.V. Carozzi, 1967, New York, Hafner Publishing.

Barry, R.G. 2008. Mountain weather and climate. Third edition. Cambridge, etc., Cambridge University Press.

Bozhinskiy, A.N., M.S. Krass and V.V. Popovnin. 1986. Role of debris cover in the thermal physics of glaciers. J. Glaciol., 32(111), 255-266.

Budd, W.F. and I.F. Allison. 1975. An empirical scheme for estimating the dynamics of unmeasured glaciers. IAHS Publ. 104 (Symposium at Moscow 1971 - Snow and Ice), 246-256.

Clark, D.H., M.M. Clark and A.R. Gillespie. 1994. Debris-covered glaciers in the Sierra Nevada, California, and their implications for snowline reconstructions. Quat. Res., 41(2), 139-153.

Demchenko, V.V. and L.N. Sokolov. 1982. Povyshennaya ablyatsiya I'da pod sloyem moreny $v$ usloviyakh Vostochnogo Pamira [Increased ice ablation under a moraine layer in the conditions of the eastern Pamirs]. Mater. Glyatsiol. Issled. 45, 119-121. [In Russian.]

Drewry, D. 1986. Glacial geologic processes. London, Edward Arnold.

Han, H., Y. Ding and S. Liu. 2006. A simple model to estimate ice ablation under a thick debris layer. J. Glaciol., 52(179), 528-536.

Hewitt, K. 2009. Rock avalanches that travel onto glaciers and related developments, Karakoram Himalaya, Inner Asia. Geomorphology, 103(1), 66-79.

Hewitt, K., J.J. Clague and J.F. Orwin. 2008. Legacies of catastrophic rock slope failures in mountain landscapes. EarthSci. Rev., 87(1-2), 1-38.

Kayastha, R.B., Y. Takeuchi, M. Nakawo and Y. Ageta. 2000. Practical prediction of ice melting beneath various thickness of debris cover on Khumbu Glacier, Nepal using a positive degreeday factor. IAHS Publ. 264 (Symposium at Seattle 2000 - DebrisCovered Glaciers), 71-81.

Khan, M.I. 1989. Ablation on Barpu Glacier, Karakoram Himalaya, Pakistan: a study of melt processes on a faceted, debris-covered ice surface. (MSc thesis, Wilfrid Laurier University.)

Khodakov, V.G. 1972. Raschet ablyatsii I'da pod sloyem moreny [Calculation of ice ablation under moraine layer]. Mater. Glyatsiol. Issled. 20, 105-108. [In Russian.]

Kirkbride, M.P. 1989. The influence of sediment budget on geomorphic activity of the Tasman Glacier, Mount Cook National Park, New Zealand. (PhD thesis, University of Canterbury.)

Kirkbride, M.P. and A.J. Dugmore. 2003. Glaciological response to distal tephra fallout from the 1947 eruption of Hekla, south Iceland. J. Glaciol., 49(166), 420-428.

Konovalov, V. 2000. Computations of melting under moraine as a part of a regional modelling of glacier runoff. IAHS Publ. 264 (Symposium at Seattle 2000 - Debris-Covered Glaciers), 109-118.

Lee, J.A., T.R.H. Davies and D.H. Bell. 2009. Successive Holocene rock avalanches at Lake Coleridge, Canterbury, New Zealand. Landslides, 6(4), 287-297.

Loomis, S.R. 1970. Morphology and ablation processes on glacier ice. In Bushnell, V.C. and R.H. Ragle, eds. Icefield Ranges Research Project; scientific results. Vol. 2. Montréal, Que., Arctic Institute of North America; New York, American Geographical Society, 27-31.

Lundstrom, S.C., A.E. McCafferty and J.A. Coe. 1993. Photogrammetric analysis of 1984-89 surface altitude change of the partially debris-covered Eliot Glacier, Mount Hood, Oregon, U.S.A. Ann. Glaciol., 17, 167-170.

Mattson, L.E. 2000. The influence of a debris cover on the midsummer discharge of Dome Glacier, Canadian Rocky Mountains. IAHS Publ. 264 (Symposium in Seattle 2000 - DebrisCovered Glaciers), 25-33. 
Mattson, L.E. and J.S. Gardner. 1989. Energy exchange and ablation rates on the debris-covered Rakhiot Glacier, Pakistan. Z. Gletscherkd. Glazialgeol., 25(1), 17-32.

Mattson, L.E., J.S. Gardner and G.J. Young. 1993. Ablation on debris covered glaciers: an example from the Rakhiot Glacier, Punjab, Himalaya. IAHS Publ. 218 (Symposium at Kathmandu 1992 - Snow and Glacier Hydrology), 289-296.

McSaveney, M.J. 1975. The Sherman Glacier rock avalanche of 1964 - its emplacement and subsequent effects on the glacier beneath it. (PhD thesis, The Ohio State University.)

McSaveney, M.J. and T.R.H. Davies. 2007. Rockslides and their motion. In Sassa, K., H. Fukuoka, F. Wang and G. Wang, eds. Progress in landslide science. Berlin, etc., Springer-Verlag, 113-133.

Mihalcea, C., C. Mayer, G. Diolaiuti, A. Lambrecht, C. Smiraglia and G. Tartari. 2006. Ice ablation and meteorological conditions on the debris-covered area of Baltoro glacier, Karakoram, Pakistan. Ann. Glaciol., 43, 292-300.

Nakawo, M. and B. Rana. 1999. Estimate of ablation rate of glacier ice under a supraglacial debris layer. Geogr. Ann., Ser. A, 81(4), 695-701.

Nakawo, M. and G.J. Young. 1981. Field experiments to determine the effect of a debris layer on ablation of glacier ice. Ann. Glaciol., 2, 85-91.

Nakawo, M. and G.J. Young. 1982. Estimate of glacier ablation under a debris layer from surface temperature and meteorological variables. J. Glaciol., 28(98), 29-34.

Nicholson, L. and D.I. Benn. 2006. Calculating ice melt beneath a debris layer using meteorological data. J. Glaciol., 52(178), 463-470.

Oerlemans, J. 2001. Glaciers and climate change. Lisse, etc., A.A. Balkema.

Østrem, G. 1965. Problems of dating ice-cored moraines. Geogr. Ann., Ser. A, 47(1), 1-38.
Paterson, W.S.B. 1994. The physics of glaciers. Third edition. Oxford, etc., Elsevier.

Popovnin, V.V. and A. Rozova. 2002. Influence of sub-debris thawing on ablation and runoff of the Djankuat Glacier in the Caucasus. Nord. Hydrol., 33(1), 75-94.

Post, A.S. 1968. Effects on glaciers. In The Great Alaska Earthquake of 1964. Vol. 3: Hydrology, Part A. Washington, DC, National Academy of Sciences, 266-308. (NAS Publication 1603.)

Rogerson, R.J., M.E. Olson and D. Branson. 1986. Medial moraines and surface melt on glaciers of the Torngat Mountains, northern Labrador, Canada. J. Glaciol., 32(112), 350-354.

Röhl, K. 2008. Characteristics and evolution of supraglacial ponds on debris-covered Tasman Glacier, New Zealand. J. Glaciol., 54(188), 867-880.

Sharp, R.P. 1949. Studies of superglacial debris on valley glaciers. Am. J. Sci., 247(5), 289-315.

Shulmeister, J., T.R. Davies, D.J.A. Evans, O.M. Hyatt and D.S. Tovar. 2009. Catastrophic landslides, glacier behaviour and moraine formation: a view from an active plate margin. Quat. Sci. Rev., 28(11-12), 1085-1096.

Slaymaker, O. and R.E.J. Kelly. 2007. The cryosphere and global environmental change. Malden, MA, Blackwell Publishing.

Tangborn, W. and B. Rana. 2000. Mass balance and runoff of the partially debris-covered Langtang Glacier, Nepal. IAHS Publ. 264 (Symposium at Seattle 2000 - Debris-Covered Glaciers), 99-108.

Yamaguchi, S., T. Matsumoto, T. Sawagaki, Y.D. Murav'yev, A.A. Ovsyannikov and R. Naruse. 2000. Glaciological research of Bilchenock Glacier in Kamchatka, 1998. Bull. Glaciol. Res., 17, 43-50

Yamaguchi, S., T. Sawagaki, T. Matsumoto, Y.D. Muravyev and R. Naruse. 2007. Influence of debris cover on ogive-like surface morphology of Bilchenok Glacier in Kamchatka. Arct. Antarct. Alp. Res., 39(2), 332-339.

MS received 5 October 2009 and accepted in revised form 19 April 2010 